\title{
Pubertal Development in 17Beta-Hydroxysteroid Dehydrogenase Type 3 Deficiency
}

\author{
Olaf Hiort $^{a}$ Louise Marshall ${ }^{a}$ Wiebke Birnbaum $^{a}$ Lutz Wünsch ${ }^{b}$ \\ Paul-Martin Holterhus ${ }^{c}$ Ulla Döhnert ${ }^{a}$ Ralf Werner ${ }^{\mathrm{a}}$ \\ ${ }^{a}$ Division of Experimental Paediatric Endocrinology and Diabetes, Department of Paediatric and Adolescent \\ Medicine, University of Lübeck, Lübeck, Germany; ${ }^{b}$ Department of Paediatric Surgery, University of Lübeck, \\ Lübeck, Germany; ' Department of General Paediatrics, University of Kiel, Kiel, Germany
}

\section{Established Facts}

- Disorders of sex development due to $17 \beta$-hydroxysteroid dehydrogenase deficiency are associated with a variable phenotype, and gender development is very difficult to predict.

\section{Novel Insights}

- $46, \mathrm{XY}$ patients with $17 \beta$-hydroxysteroid dehydrogenase deficiency have testosterone levels at the time of puberty that mainly depend on the underlying mutation of the HSD17B3 gene. These mutations may be predictors of pubertal development and hence of gender development.

\section{Keywords}

Sex development $\cdot$ Puberty $\cdot 17 \beta$-hydroxysteroid dehydrogenase deficiency · Testosterone synthesis

\begin{abstract}
Background: 17 $\beta$-hydroxysteroid dehydrogenase(17 $\beta$-HSD) type 3 deficiency is an autosomal recessive disorder with diminished testosterone synthesis and consequently underandrogenisation. 46,XY patients with 17ß-HSD type 3 deficiency are often assigned a female sex at birth but have a high virilisation potential at the time of puberty. Methods: We studied four $46, \mathrm{XY}$ patients with $17 \beta$-HSD type 3 deficiency at puberty with regard to the underlying mutations, the hormone values, and the clinical findings. Results: Three
\end{abstract}

\section{KARGER}

(c) 2016 S. Karger AG, Basel

E-Mail karger@karger.com

www.karger.com/hrp patients were initially assigned a female sex and 1 was assigned a male sex. All had relevant mutations in the HSD17B3 gene. The 2 patients with deleterious mutations had lower testosterone values at the time of puberty than the patients with possible residual activity of $17 \beta-$ HSD type 3 . One of the latter patients changed to male gender. Conclusion: All 4 patients with $17 \beta-\mathrm{HSD}$ type 3 deficiency synthesized relevant amounts $(>0.7 \mu \mathrm{g} / \mathrm{L}$ ) of testosterone at puberty, which lead to variable androgenisation. In patients with presumable residual activity of the mutated enzyme, testosterone values in the male reference range can be achieved, thereby inducing male pubertal development. These patients should possibly be assigned a male sex. Any surgical intervention should be avoided until the patients are old enough to consider their options of medical and surgical intervention.

두 2016 S. Karger AG, Base

Prof. Dr. med. Olaf Hiort

Division of Experimental Paediatric Endocrinology and Diabetes Department of Paediatric and Adolescent Medicine, University of Lübeck Ratzeburger Allee 160, DE-23560 Lübeck (Germany)

E-Mail olaf.hiort@uksh.de 


\section{Introduction}

Differences or disorders of sex development (DSD) constitute an array of mostly hereditary conditions with a divergence of chromosomal, gonadal, and phenotypic sex. While some causes of DSD are well described, others remain elusive with regard to the underlying genetic abnormality. Even in those cases, in which the biochemical and genetic conditions are well described, the decisionmaking process of sex assignment and the overall management of the affected individuals are difficult [1].

$17 \beta$-hydroxysteroid dehydrogenase ( $17 \beta$-HSD) deficiency is a disorder affecting 46,XY individuals, leading to a moderate to severe underandrogenisation in utero due to defective testosterone synthesis. It is an autosomal recessive disorder with mutations in the HSD17B3 gene on chromosome 9q22 coding for the isoenzyme type 3 within the family of $17 \beta$-HSDs [2, 3]. $17 \beta$-HSD type 3 is highly expressed in the developing testes, leading to conversion of $\Delta 4$-androstenedione to testosterone, which acts locally due to high intratesticular concentrations and is also released into the periphery for further endocrine action [4]. The isoenzyme $17 \beta$-HSD type 5 is able to contribute to conversion from androstenedione to testosterone especially postnatally and at the time of puberty [5].

Therefore, 46,XY individuals with $17 \beta$-HSD type 3 deficiency are often born with female-appearing external genitalia with only slight androgenisation [6-9]. The development of prostate, seminal vesicles, and epididymis is variable. The testes are localized in the inguinal canal or even abdominal. The children are often assigned a female sex and the diagnosis may be missed until childhood when hernias may occur or even be deferred until adolescence when female pubertal development is lacking. Instead, at puberty a massive surge of androstenedione is observed with variable conversion to testosterone [10]. The patients may demonstrate enlargement of the phallic structures, deepening of the voice, male body appearance and male secondary hair growth. The virilisation has been attributed to 3 peculiarities. First, androstenedione is a weak androgen acting through the androgen receptor, thereby inducing androgenic effects itself [11]. Second, testosterone synthesis occurs through an alternative pathway utilizing mainly $17 \beta$-HSD type 5 . It has recently been demonstrated that $17 \beta$-HSD type 5 is expressed in Leydig cells and that therefore testosterone in $17 \beta-\mathrm{HSD}$ deficiency is of testicular origin $[4,5]$. Third, residual activity of the mutated $17 \beta$-HSD type 3 enzyme may contribute to a pubertal testosterone synthesis [2].
Additionally, patient descriptions indicate a high variability of testosterone levels in pubertal 46,XY subjects with $17 \beta$-HSD deficiency [12]. It remains unclear if the testosterone synthesis contributes to gender identity in these individuals, but a gender change has been reported frequently in $17 \beta$-HSD deficiency and also in $5 a$-reductase deficiency, especially in clusters from developing countries [12-15]. In Western countries, gonadectomy is often performed early in life and the $46, \mathrm{XY}$ children with $17 \beta$-HSD deficiency are raised in the female gender $[16,17]$. The difficult and often arbitrary mode of sex assignment has been discussed in an earlier report by us $[18]$ and others $[15,16]$.

Here we describe four 46,XY patients with $17 \beta$-HSD deficiency seen at the University of Lübeck for assessment at the time of puberty with their gonads in situ. Genetic and endocrine findings as well as gender role and consequently sex assignment are discussed.

\section{Patients and Methods}

\section{Patients}

Patient 1 came to our attention at the age of $15 ; 11$ years. She reported that she had noticed that pubertal development had not proceeded in a female fashion for 4 years. She had observed no breast development, instead the clitoris had grown. Her father reported that a hernia repair had been performed at the age of 2 years and testes had been found, but no consequences had been suggested. Prior to presenting at the University of Lübeck, a 46,XY karyotype had been analysed. To prevent acne and to promote breast development, she had been put on a therapy with cyproterone acetate and estradiol valerate. Physical examination in our institution showed a slim individual with moderate to severe acne in the face, a hoarse voice, breast development corresponding to Tanner stage B2, pubic hair corresponding to Tanner stage $\mathrm{PH} 4$, and a clitoris of $5 \mathrm{~cm}$ in length. A thorough investigation in general anaesthesia showed a short, female-appearing urethra and a vagina of $5 \mathrm{~cm}$ in length. The gonads were located in the inguinal canal. Laboratory investigations for endocrine values and molecular genetic analysis of the HSD17B3 gene were initiated.

At psychological assessment the patient initially described ambivalence. On the one hand, the patient wished to remain in the female gender; on the other hand, she expressed the burden of secrecy and shame within the family and the bearing of the surgical intervention. A consensus conference at our centre favoured removal of the gonads, which was discussed thoroughly with the patient who then consented to the gonadectomy. The gonads histologically demonstrated some interstitial fibrosis and no spermatogenesis, but otherwise normal testicular appearance. After gonadectomy, the testosterone level fell immediately and the patient was put on estradiol valerate $2 \mathrm{mg}$ daily for substitution [5].

Patient 2 came to medical attention at the age of $16 ; 6$ years for primary amenorrhea at another institution. An elevated testosterone level was found, and on ultrasound a uterus was not detected. Chromosomal analysis revealed a 46,XY karyotype, and the patient was referred to the University of Lübeck. At this time, she was 
17;9 years old, was suffering from obesity, and had slight acne in the face. She had pseudogynecomastia, but the glandular breast tissue was only $2-3 \mathrm{~cm}$ in diameter. Her pubic hair was corresponding to Tanner stage $\mathrm{PH} 5$. On gynaecologic examination, her labia minora were slightly fused in the dorsal part and the clitoris was enlarged to $2.5 \mathrm{~cm}$. The vagina was short with a length of $3 \mathrm{~cm}$. Laboratory and genetic analyses confirmed the diagnosis of $17 \beta$-HSD type 3 deficiency. The patient opted for staying in the female gender and proceeded to gonadectomy at an outside hospital. The gonads were localized at the inner inguinal canal and demonstrated apparently histologically normal testicular tissue.

Patient 3 came to initial attention at the age of 13;6 years. She had been raised female without major peculiarities. At the time of puberty, virilisation was marked. At the initial presentation at the Department of Paediatrics at the University of Kiel, a 46,XY karyotype was determined and further laboratory and genetic testing was initiated, which proved $17 \beta$-HSD type 3 deficiency. The patient voiced strongly that since the age of 11 years, a male identity had been felt. On physical examination at the age of 14;1 years, gender change to male had already been pursued after thorough evaluation by experts from sexual medicine and psychology. At this time, the physical appearance was male without any breast development; pubic hair corresponded to Tanner stage PH4. The phallus was short and bent due to severe chorda, but on ultrasound erectile tissue was present. Several surgical procedures were performed to move the inguinal testes into the scrotum and to perform straightening of the penis with build-up of a neo-urethra.

Patient 4 has been described earlier in detail in his childhood appearance [18]. He and his younger sibling had been born with ambiguous genitalia. Genetic analysis revealed a 46,XY karyotype in both individuals and later $17 \beta-H S D$ type 3 deficiency was proved by mutation analysis. While patient 4 was raised male, the younger sibling was raised female and the gonads had been removed. Patient 4 underwent several hypospadias repair operations at outside hospitals and presented again at the age of 16;6 years at the University of Lübeck. He reported to have gone through spontaneous puberty without hormone supplementation. He had a muscular male habitus and shaved 2 times weekly. Penile length was $5 \mathrm{~cm}$ with a diameter of $2.5 \mathrm{~cm}$ and normal urethral opening after hypospadias repair. Pubic hair corresponded to Tanner stage PH5. He reported erections and ejaculations but did not consent to sperm analysis. Testicular volume was $15 \mathrm{~mL}$ and both testes were in the scrotum. Laboratory investigations were performed.

Except for patient 4, molecular genetic investigations for carrier status of the HSD17B3 mutations were not performed in the parents. All patients and legal guardians consented to the use of medical data for scientific purposes.

DNA Analysis

DNA was extracted from peripheral blood cells by standard procedures. The HSD17B3 gene was amplified by PCR in 11 parts spanning the individual exons including the intron-exon boundaries. All amplicons were directly sequenced, and sequences were analysed on an ABI Applied 3130/Genetic Analyser. After the analysis, finished samples were then integrated using SeqScape (version 2.5) software (ABI).

Hormone Analysis

Blood was drawn at the age of $15 ; 11-17 ; 11$ years, when the patients were presumably advanced in pubertal development. LH and FSH were measured by standard assays on an Elecsys 2010-3 (Roche, Germany). Androstenedione and testosterone were either measured by immunometric analysis (Immulite 2000, Siemens, Germany, for androstenedione, and Elecsys 2010-3, Roche, for testosterone) or by radioimmunoassay after extraction (patient 3 ) or by LC-MSMS as described by Kulle et al. [19] in patient 4.

\section{Results}

In all 4 patients a relevant mutation in the $H S D 17 B 3$ gene was found. Patients 1 and 2 carried the common splice-site mutation c. $277+4 \mathrm{~A}>\mathrm{T}$ in a homozygous fashion. This mutation was initially described by Boehmer et al. [7] as c.325+4 A>T and is known to disrupt the function of $17 \beta$-HSD type 3 completely. Patient 3 carried this mutation in a heterozygote fashion and a second heterozygous mutation, p.N130S, which was initially described by Moghrabi et al. [20]. These authors found that the p.N130S mutation led to a severe albeit not complete loss of enzymatic activity. Patient 4 carried this p.N130S mutation in a heterozygote fashion and an additional heterozygote well-described mutation, p.R80Q, which has residual enzymatic activity [2, 12].

The hormone values and the adult male reference ranges are shown in Table 1. All patients had slightly elevated LH levels, pointing towards hypergonadotrophic hypogonadism. However, the testosterone levels were quite variable. While the testosterone levels were below the adult male reference range in patients 1 and 2 , the values in patients 3 and 4 were significantly higher and in the lower- to mid-adult reference range. Interestingly, FSH levels were also highly variable, and especially in patient 3 highly elevated, pointing towards a common testicular failure. In all patients, the testosterone to androstenedione ratio was significantly reduced $(<0.8$ according to [21-23]), giving biochemical evidence of $17 \beta$-HSD type 3 deficiency.

\section{Discussion}

$17 \beta$-HSD type 3 deficiency is a distinct disorder of testosterone biosynthesis leading to 46,XY DSD. The patients described here fit well with the previous clinical descriptions of this condition. In all patients, a relevant mutation in the HSD17B3 gene was detected. Two patients had the common c. $277+4 \mathrm{~A}>\mathrm{T}$ mutation in a homozygous fashion, which seems to be prevalent in European Caucasians, corresponding to a complete loss of function of the $17 \beta$-HSD type 3 enzyme. Interestingly, testosterone 
Table 1. Patients' hormone levels drawn at the given age, as well as the underlying mutation in the HSD17B3 gene with the estimate of enzyme activity published in the literature (see text)

\begin{tabular}{|c|c|c|c|c|}
\hline & \multicolumn{4}{|l|}{ Patient } \\
\hline & 1 & 2 & 3 & 4 \\
\hline Age, years & $15 ; 11$ & $17 ; 9$ & $17 ; 10$ & $16 ; 5$ \\
\hline Gender at birth/puberty & female/female & female/female & female/male & male/male \\
\hline $\mathrm{LH}, \mathrm{U} / \mathrm{L}$ & 15 & 13 & 23.23 & 8.77 \\
\hline FSH, U/L & 5.2 & 4.1 & 60.5 & 12.7 \\
\hline Testosterone, $\mu \mathrm{g} / \mathrm{L}$ & 1.13 & 0.73 & 3.51 & 4.09 \\
\hline Androstenedione, $\mu \mathrm{g} / \mathrm{L}$ & 8.56 & 3.35 & 10 & 10 \\
\hline Testosterone/androstenedione ratio & 0.13 & 0.22 & 0.35 & 0.41 \\
\hline Mutations & $\begin{array}{l}\text { c. } 277+4 \mathrm{~A}>\mathrm{T} \\
\text { (homozygous) }\end{array}$ & $\begin{array}{l}\text { c. } 277+4 \mathrm{~A}>\mathrm{T} \\
\text { (homozygous) }\end{array}$ & $\begin{array}{l}\text { c. } 277+4 \text { A }>T ; \\
\text { p.N130S }\end{array}$ & $\begin{array}{l}\text { p.R80Q; } \\
\text { p.N130S }\end{array}$ \\
\hline Approximate enzyme activity, \% & 0 & 0 & $0 / \sim 15$ & $\sim 20 / \sim 15$ \\
\hline
\end{tabular}

Adult male reference ranges are as follows: 0.4-7.0 U/L ( $\mathrm{LH}), 2.6-11.0 \mathrm{U} / \mathrm{L}(\mathrm{FSH}), 3.5-9.7 \mu \mathrm{g} / \mathrm{L}$ (testosterone), 2.06-3.75 $\mu \mathrm{g} / \mathrm{L}$ (androstenedione), and $>0.8$ (testosterone/androstenedione ratio). The gender assignment at birth and the gender preference at puberty are described.

levels were measurable and above the female reference range for age $(0.2-0.37 \mu \mathrm{g} / \mathrm{L})$, pointing towards an increased testosterone synthesis. In patient 1 this may be due to the increased androstenedione value; however, in patient 2 the peripheral androstenedione value was within the usual female reference range $(1.0-4.95 \mu \mathrm{g} / \mathrm{L}$, for Immulite 2000, women Tanner stage 5).

In patients 3 and 4, two relevant heterozygous mutations in the HSD17B3 gene were present. According to Moghrabi et al. [20], the p.N130S exchange leads to a severe functional deficit of the mutated enzyme, while the p.R80Q enzyme has even more residual function [2] (Table 1). We presume that the testosterone values in these patients are due to a mixture of both, residual enzymatic activity of $17 \beta$-HSD type 3 and additional conversion of the elevated androstenedione through $17 \beta$-HSD type 5 [5].

While the cohort is small, it seems noteworthy that all patients would be presumed to suffer from consecutive gonadal failure; patient 3 from a global testicular insufficiency because of the highly elevated FSH, and all patients because of the slightly elevated LH (Table 1). However, as disease-specific reference intervals for $17 \beta$-HSD deficiency are not available, the latter interpretation is weak and the elevation of LH might reflect the slightly altered regulatory mechanisms due to the diminished testosterone synthesis by the mutated $17 \beta$-HSD type 3 .

Patients 3 and 4 chose to change to male gender or remained in the male gender. Their testosterone values are at a much higher range than in the 2 patients who re- mained in the female gender initially assigned. Testosterone values of patients 3 and 4 are at the lower end of the adult male reference range (Table 1) and in the mid-reference intervals for males at pubertal Tanner stages 3-4. Testicular function in these 2 individuals leads to an enormous surge of androstenedione with values high above the usual reference range and a respective conversion to testosterone. Patient 4 reached a testicular volume of 15 $\mathrm{mL}$ and had only slightly elevated FSH levels above the usual male reference range, which makes relevant spermatogenesis likely, although he did not consent to a semen analysis. Also, we do not have any information on spermatogenesis in patient 3 as yet.

Whether these values correspond to intrauterine testosterone synthesis and action remains elusive at this time. However, patient 3 was raised as a female during childhood and the genital appearance was judged unequivocally female at several paediatric clinical investigations. We presume that the prenatal testosterone synthesis was at least not high enough to induce relevant intrauterine virilisation.

From these descriptions we conclude that the clinical course of 46,XY patients with $17 \beta$-HSD type 3 deficiency is indeed highly variable. Especially when a residual activity of mutated enzymes can be presumed, a male gender identity may arise despite initially female-appearing genitalia. Therefore, any irrevocable decision regarding removal of the gonads or genital surgery should be postponed until the patient is able to consent to these procedures or is old enough to review his/her options. Fur- 
thermore, some patients with $17 \beta-H S D$ deficiency may have testicular functions enabling them to synthesize testosterone amounts comparable to normal males, thereby not necessitating any hormone substitution in adolescence and adulthood, and may even be fertile. Longterm outcome studies of these conditions are desperately needed.

\section{Acknowledgement}

The authors are participants of the COST (European Cooperation of Science and Technology) Action BM1303 DSDnet. Funding of these studies is in part possible through intramural funding of the University of Lübeck (SPP "Medical Genetics").

\section{Disclosure Statement}

The authors have no conflicts of interest to disclose.

\section{References}

1 Hughes IA, Houk C, Ahmed SF, Lee PA: Consensus statement on management of intersex disorders. Arch Dis Child 2006;91:554-563.

-2 Geissler WM, Davis DL, Wu L, Bradshaw KD, Patel S, Mendonca BB, Elliston KO, Wilson JD, Russell DW, Andersson S: Male pseudohermaphroditism caused by mutations of testicular 17beta-hydroxysteroid dehydrogenase 3. Nat Genet 1994;7:34-39.

-3 George MM, New MI, Ten S, Sultan C, Bhangoo A: The clinical and molecular heterogeneity of $17 \beta \mathrm{HSD}-3$ enzyme deficiency. Horm Res Paediatr 2010;74:229-240.

-4 Andersson S, Geissler WM, Wu L, Davis DL, Grumbach MM, New MI, Schwarz HP, Blethen SL, Mendonca BB, Bloise W, Witchel SF, Cutler GB, Griffin JE, Wilson JD, Russel DW: Molecular genetics and pathophysiology of 17 beta-hydroxysteroid dehydrogenase 3 deficiency. J Clin Endocrinol Metab 1996;81: 130-136.

5 Werner R, Kulle A, Sommerfeld I, Riepe FG, Wudy S, Hartmann MF, Merz H, Döhnert U, Bertelloni S, Holterhus PM, Hiort O: Testosterone synthesis in patients with $17 \beta$-hydroxysteroid dehydrogenase 3 deficiency. Sex Dev 2012;6:161-168.

6 Lee YS, Kirk JMW, Stanhope RG, Derek IJ, Harland S, Auchus RJ, Andersson S, Hughes IA: Phenotypic variability in 17beta-hydroxysteroid dehydrogenase-3 deficiency and diagnostic pitfalls. Clin Endocrinol 2007;67: 20-28.

7 Boehmer AL, Brinkmann AO, Sandkuijl LA, Halley DJ, Niermeijer MF, Andersson S, de Jong FH, Kayserili H, de Vroede MA, Otten $\mathrm{BJ}$, Rouwé CW, Mendonca BB, Rodrigues C, Bode HH, De Ruiter PE, Delemarre-van de Waal HA, Drop SL: $17 \beta$-hydroxysteroid dehydrogenase deficiency: diagnosis, phenotypic variability, population genetics, and worldwide distribution of ancient and de novo mutations. J Clin Endocrinol Metab 1999;84: 4713-4721.
8 Twesten W, Holterhus PM, Sippell WG, Morlot $\mathrm{M}$, Schumacher $\mathrm{H}$, Schenk B, Hiort O Clinical, endocrine, and molecular genetic findings in patients with $17 \beta$-hydroxysteroid dehydrogenase deficiency. Horm Res 2000;53: 26-31.

-9 Bertelloni S, Maggio MC, Federico G, Baroncelli G, Hiort O: 17beta-hydroxysteroid dehydrogenase-3 deficiency: a rare endocrine cause of male-to-female sex reversal. Gynecol Endocrinol 2006;22:488-494.

10 Bertelloni S, Balsamo A, Giordani L, Fischetto R, Russo G, Delvecchio M, Gennari M, Nicoletti A, Maggio MC, Concolino D, Cavallo L, Cicognani A, Chiumello G, Hiort O, Baroncelli GI, Faienza MF: 17beta-hydroxysteroid dehydrogenase-3 deficiency: from pregnancy to adolescence. J Endocrinol Invest 2009;32: 666-670.

11 Holterhus PM, Piefke S, Hiort O: Anabolic steroids, testosterone-precursors and virilizing androgens induce distinct activation profiles of androgen responsive promoter constructs. J Steroid Biochem Mol Biol 2002;82: 269-275.

12 Rösler A, Silverstein S, Abeliovich D: A (R80Q) mutation in the 17 beta-hydroxysteroid dehydrogenase type 3 gene among Arabs of Israel is associated with pseudohermaphroditism in males and normal asymptomatic females. J Clin Endocrinol Metab 1996;81: 1827-1831.

13 Rosler A: 17 beta-hydroxysteroid dehydrogenase 3 deficiency in the Mediterranean population. Pediatr Endocrinol Rev 2006;3(suppl3): 455-461.

14 Hochberg Z, Chayen R, Reis N, Falik Z, Mackler A, Monitzur M, Ohana N, Hiort O: Clini$\mathrm{cal}$ and genetic findings in male and female patients with $5 a$-reductase deficiency. J Clin Endocrinol Metab 1996;81:2821-2827.

15 Cohen-Kettenis PT: Gender change in 46,XY persons with 5alpha-reductase-2 deficiency and 17beta-hydroxysteroid dehydrogenase-3 deficiency. Arch Sex Behav 2005;34:399-410.
6 Wisniewski AB, Mazur T: 46,XY DSD with female or ambiguous external genitalia at birth due to androgen insensitivity syndrome, $5 a-$ reductase-2 deficiency, or $17 \beta$-hydroxysteroid dehydrogenase deficiency: a review of quality of life outcomes. Int J Pediatr Endocrinol 2009, DOI: $10.1155 / 2009 / 567430$.

17 Hiort O, Reinecke S, Thyen U, Jürgensen $M$, Holterhus PM, Schön D, Richter-Appelt $\mathrm{H}$ : Aspects of puberty in disorders of somatosexual differentiation. J Pediatr Endoc Met 2003;16:297-306.

18 Jurgensen M, Hampel E, Hiort O, Thyen U: Any decision better than none: decision-making about sex of rearing for siblings with $17 \mathrm{be}$ ta-hydroxysteroid dehydrogenase- 3 deficiency. Arch Sex Behav 2006;35:359-371.

19 Kulle AE, Riepe FG, Melchior D, Hiort O, Holterhus PM: A novel ultrapressure liquid chromatography tandem mass spectrometry method for the simultaneous determination of androstenedione, testosterone, and dihydrotestosterone in pediatric blood samples: age- and sex-specific reference data. J Clin Endocrinol Metab 2010;95:2399-2409.

20 Moghrabi N, Hughes IA, Dunaif A, Andersson S: Deleterious missense mutations and silent polymorphism in the human 17beta-hydroxysteroid dehydrogenase 3 gene (HSD17B3). J Clin Endocrinol Metab 1998; 83:2855-2860.

21 Mendonca BB, Gomes NL, Costa EMF, Inacio M, Martin RM, Nishi MY, Carvalho FM, Tibor FD, Domenice S: 46,XY disorder of sex development (DSD) due to 17beta-hydroxysteroid dehydrogenase type 3 deficiency. J Steroid Biochem Mol Biol 2016, DOI: 10.1016/ j.jsbmb.2016.05.002.

22 Ahmed SF, Iqbal A, Hughes IA: The testosterone:androstendione ratio in male undermasculinization. Clin Endocrinol 2000;53:697-702.

23 Bertelloni S, Dati E, Hiort O: Diagnosis of 17beta-hydroxysteroid dehydrogenase deficiency. Expert Rev Endocrinol Metab 2009;4: 53-65. 